\title{
Phenolic Profile and Antioxidant Potential of Leaves from Selected Cotoneaster Medik. Species
}

\author{
Agnieszka Kicel ${ }^{1, *}$, Piotr Michel ${ }^{1}$, Aleksandra Owczarek ${ }^{1}$, Anna Marchelak ${ }^{1}$, \\ Dorota Żyżelewicz $^{2}$, Grażyna Budryn ${ }^{2}$, Joanna Oracz ${ }^{2}$ and Monika Anna Olszewska ${ }^{1}$ \\ 1 Department of Pharmacognosy, Faculty of Pharmacy, Medical University of Lodz, 1 Muszynskiego, \\ 90-151 Lodz, Poland; piotr.michel@umed.lodz.pl (P.M.); aleksandra.owczarek@umed.lodz.pl (A.O.); \\ anna.marchelak@umed.lodz.pl (A.M.); monika.olszewska@umed.lodz.pl (M.A.O.) \\ 2 Institute of Food Technology and Analysis, Faculty of Biotechnology and Food Science, \\ Lodz University of Technology, 4/10 Stefanowskiego, 90-924 Lodz, Poland; \\ dorota.zyzelewicz@p.lodz.pl (D.Ż.); grazyna.budryn@p.lodz.pl (G.B.); joanna.oracz@p.lodz.pl (J.O.) \\ * Correspondence: agnieszka.kicel@umed.lodz.pl; Tel.: +48-42-6779166
}

Academic Editor: Isabel C. F. R. Ferreira

Received: 29 April 2016; Accepted: 20 May 2016; Published: 26 May 2016

\begin{abstract}
The antioxidant efficiency of 70\% aqueous methanolic extracts from the leaves of twelve selected Cotoneaster Medik. species was evaluated using four complementary in vitro tests based on SET- (single electron transfer) and HAT-type (hydrogen atom transfer) mechanisms (DPPH, FRAP, $\mathrm{O}_{2}{ }^{\bullet-}$ and $\mathrm{H}_{2} \mathrm{O}_{2}$ scavenging assays). The samples exhibited the dose-dependent responses in all assays with activity parameters of $\mathrm{EC}_{50}=18.5-34.5 \mu \mathrm{g} / \mathrm{mL}$ for DPPH; $0.9-3.8 \mathrm{mmol} \mathrm{Fe}{ }^{2+} / \mathrm{g}$ for FRAP; $\mathrm{SC}_{50}=27.7-74.8 \mu \mathrm{g} / \mathrm{mL}$ for $\mathrm{O}_{2}{ }^{\bullet-}$; and $\mathrm{SC}_{50}=29.0-91.3 \mu \mathrm{g} / \mathrm{mL}$ for $\mathrm{H}_{2} \mathrm{O}_{2}$. Significant linear correlations $(|r|=0.76-0.97, p<0.01)$ between activity parameters and total contents of phenolics (5.2\%-15.4\% GAE) and proanthocyanidins (2.1\%-15.0\% CYE), with weak or no effects for chlorogenic acid isomers $(0.69 \%-2.93 \%)$ and total flavonoids $(0.28 \%-1.40 \%)$ suggested that among the listed polyphenols, proanthocyanidins are the most important determinants of the tested activity. UHPLC-PDA-ESI-QTOF-MS analyses led to detection of 34 polyphenols, of which 10 B-type procyanidins, 5 caffeoylquinic acids and 14 flavonoids were identified. After cluster analysis of the data matrix, the leaves of Cotoneaster zabelii, C. splendens, C. bullatus, C. divaricatus, C. hjelmqvistii and C. lucidus were selected as the most promising sources of natural antioxidants, exhibiting the highest phenolic levels and antioxidant capacities, and therefore the greatest potential for pharmaceutical applications.
\end{abstract}

Keywords: Cotoneaster; antioxidant activity; UHPLC-PDA-ESI-QTOF-MS; HPLC-PDA; phenolic profile; phenolic, proanthocyanidin, chlorogenic acid isomer and flavonoid contents

\section{Introduction}

The oxidative stress arising from an imbalance in the total antioxidant status of the human body is believed to be involved in pathogenesis of chronic diseases usually referred to as civilization diseases, including cardiovascular and neurodegenerative disorders, cancer, metabolic syndrome, diabetes and digestive diseases [1]. Besides of endogenous defense systems, dietary antioxidants, mainly plant polyphenols, play an important role in protecting the living cells against prooxidant factors, both metabolic and external (environmental) [2]. Typical diet of Western societies, which are bearing an increasingly heavy burden of civilization diseases, is, however, poor in polyphenols and in turn rich in prooxidant xenobiotics such as hydrogenated (trans) fats, synthetic colorants and preservatives and iron/cooper-contaminated products coming from highly processed foods. The polyphenolic supplementation is therefore a generally accepted idea, which led in recent years to intensive search for 
plant-based, potent antioxidants active in prevention of chronic diseases. On the other hand, although a variety of plants have been studied for antioxidant activity and phenolic content, only few have been found to be sufficiently rich in low-molecular weight polyphenols characterized by high antioxidant potential and good bioavailability in internal applications [3,4]. Among plant families taxonomically featured by high content of low-molecular weight phenols, the Rosaceae family appears to be one of the most promising for future research. Apart from Aronia, Crataegus, Malus or Rubus species [5-8], widely known as functional or medicinal plants, the family comprises representatives being to date in traditional use only, but also worth of investigation.

Cotoneaster Medik. is a rosaceous genus of $c a$. 500 species of shrubs or small trees, occurring primarily in temperate regions of Eurasia with their center of diversity in southwestern China and the Himalayas [9]. In Poland this genus is represented by four species (C. integerrimus Medik., C. melanocarpus Lodd. ex C.K. Schneid., C. tomentosus Lindl., C. lucidus Schltdl.), whose natural range covers mainly the south-eastern region of the country. Many Cotoneaster taxons, both native and alien, are worldwide cultivated as ornamental plants, especially appreciated for their attractive leaves turning reddish-purple in autumn and decorative, orange, red or nearly black fruits [10,11]. Several species, e.g., C. melanocarpus Lodd., C. nummularia Fisch. et Mey, and C. tricolor Pajork, are used in traditional medicine, especially in Iran, Turkey, Mongolia and Tibet, to treat nasal hemorrhage, excessive menstruation, hematemesis, neonatal jaundice, fever and cough [12-14]. In different in vitro tests, they are reported to have antibacterial, anti-plasmodial, anti-cholinesterase, anti-tyrosinase, antioxidant, anti-dyslipidemic, anti-glucosidase, anti-amylase, anti-diabetic, hepatoprotective and cytotoxic activities [13,15-18]. Most of these bioactivities can be attributed to the presence of low-molecular weight polyphenols including simple phenolic acids, flavonoids [19-23], dibenzofuran derivatives [24,25], and dimeric proanthocyanidins [26]. Metabolites of this type were isolated from twigs, leaves or roots of several species known for their ethnopharmacological significance such as C. orbicularis Schlecht. [19], C. simonsii Baker [20], C. thymaefolia Hort [21], C. racemiflora Desf [22,27], C. acuminatus vern. Ruins [23] and C. horizontalis Decne [28]. Despite the fact that polyphenols are dominant constituents of the Cotoneaster species, the information on the relationship between their presence and antioxidant activity is scarce and limited to a few species [12,16,18]. As reported by Zangin et al. [16], the total phenolics of C. nummularia twigs of Turkish origin varied, depending on extract polarity, from 81 to $266 \mathrm{mg} \mathrm{GAE} / \mathrm{g}$ of the extract and were positively correlated with their antioxidant abilities, assayed by several in vitro tests. It follows that a considerably high phenolic content can be expected for plant tissues including leaves derived from other Cotoneaster species. For this reason, the objectives of this study were to screen the leaves of twelve selected Cotoneaster species with respect to their phenolic profile and antioxidant activity. The plant extracts were assayed using four complementary in vitro test systems of both single electron transfer (SET) and hydrogen atom transfer (HAT) reaction mechanisms. To identify the compounds responsible for the tested activity, the qualitative and quantitative phenolic profiles of the samples were monitored by UHPLC-PDA-ESI-QTOF-MS, HPLC-PDA and by UV-photometric methods, and the relationship between the antioxidant capacity and the phenolic content was investigated. Finally, all data were subjected to hierarchical cluster analysis to distinguish the group of species and plant materials with the greatest potential as valuable sources of natural antioxidants and candidates for in vivo studies of antioxidant protection.

\section{Results and Discussion}

\subsection{Qualitative UHPLC-PDA-ESI-QTOF-MS Profiling of Cotoneaster Leaf Phenolics}

The qualitative UHPLC-PDA-ESI-QTOF-MS profile of the 70\% aqueous methanolic extracts of the Cotoneaster leaves revealed the presence of over thirty phenolic compounds (UHPLC peaks 1-34), thirty-two of which were fully or tentatively identified by comparing their retention times, UV-Vis spectral data and MS profiles with those of the reference compounds and the literature data. Based on 
the spectral profiles (Figure 1 and Table 1; for detailed MS data see Table S1), the identified phenolics were structurally classified into three main groups comprising hydroxycinnamic acid derivatives (1-4, $6,8,29$, and 31), proanthocyanidins $(5,7,9-11,13,15-16$, and 22-23) and flavonoid glycosides $(12,14$, 17-21, 24-28, 30, and 33).

Compounds 1-4, 6, 8, 29 and 31 displayed absorption maxima at 325-328 nm and UV-Vis spectra characteristic of caffeic acid derivatives. Compounds 1, 3 and 4 based on their parent $[\mathrm{M}-\mathrm{H}]^{-}$ions at $m / z 353$ and the further MS fragmentation were classified as monocaffeoylquinic acid isomers. Compounds 1 and 3 exhibited the base ions at $m / z 191$ and the secondary ions at $m / z 179$ with intensities of $55 \%$ and $4 \%$, respectively, whereas compound 4 displayed distinctive base peak at $m / z$ 173. Consequently, based on the elution order, hierarchical discrimination keys [29] and comparison with reference compounds, both commercial and prepared in our laboratory, compounds $\mathbf{1}$, 3 and $\mathbf{4}$ were identified as 3-O-caffeoylquinic acid (NCHA, neochlorogenic acid), 5-O-caffeoylquinic acid (CHA, chlorogenic acid) and 4-O-caffeoylquinic acid (CCHA, cryptochlorogenic acid), among which only CHA was previously found in Cotoneaster species (C. simonsii, C. horizontalis, C. melanocarpus and C. nummularia) $[12,16,18,21]$. Compounds 2, 29 and 31 exhibited parent ions at $m / z$ 515, typical of dicaffeoylquinic acid isomers. Although some other fragments at $m / z 353$ and 255 were also observed for these compounds, their MS fragmentation pattern was not possible to assign to any particular structure [29]. Compound 8, revealing the $[\mathrm{M}+\mathrm{Na}-2 \mathrm{H}]^{-}$ion at $m / z 613$, the deprotonated molecular $[\mathrm{M}-\mathrm{H}]^{-}$ion at $m / z 591$ and a peak at $m / z 179$, typical of caffeic acid moiety, could be also assigned as a caffeic acid derivative. Compound 6 showed absorption maximum at $310 \mathrm{~nm}$, characteristic for $p$-coumaric acid derivative. Its MS fragmentation with deprotonated molecular ion at $m / z 337$ and secondary peak at $m / z 191$ led to the identification of 5-O-p-coumaroylquinic acid [30]. In this group, compounds 1-4 and $\mathbf{6}$ were identified in all analyzed Cotoneaster species, with predominant chlorogenic acid (CHA, 3$)$.

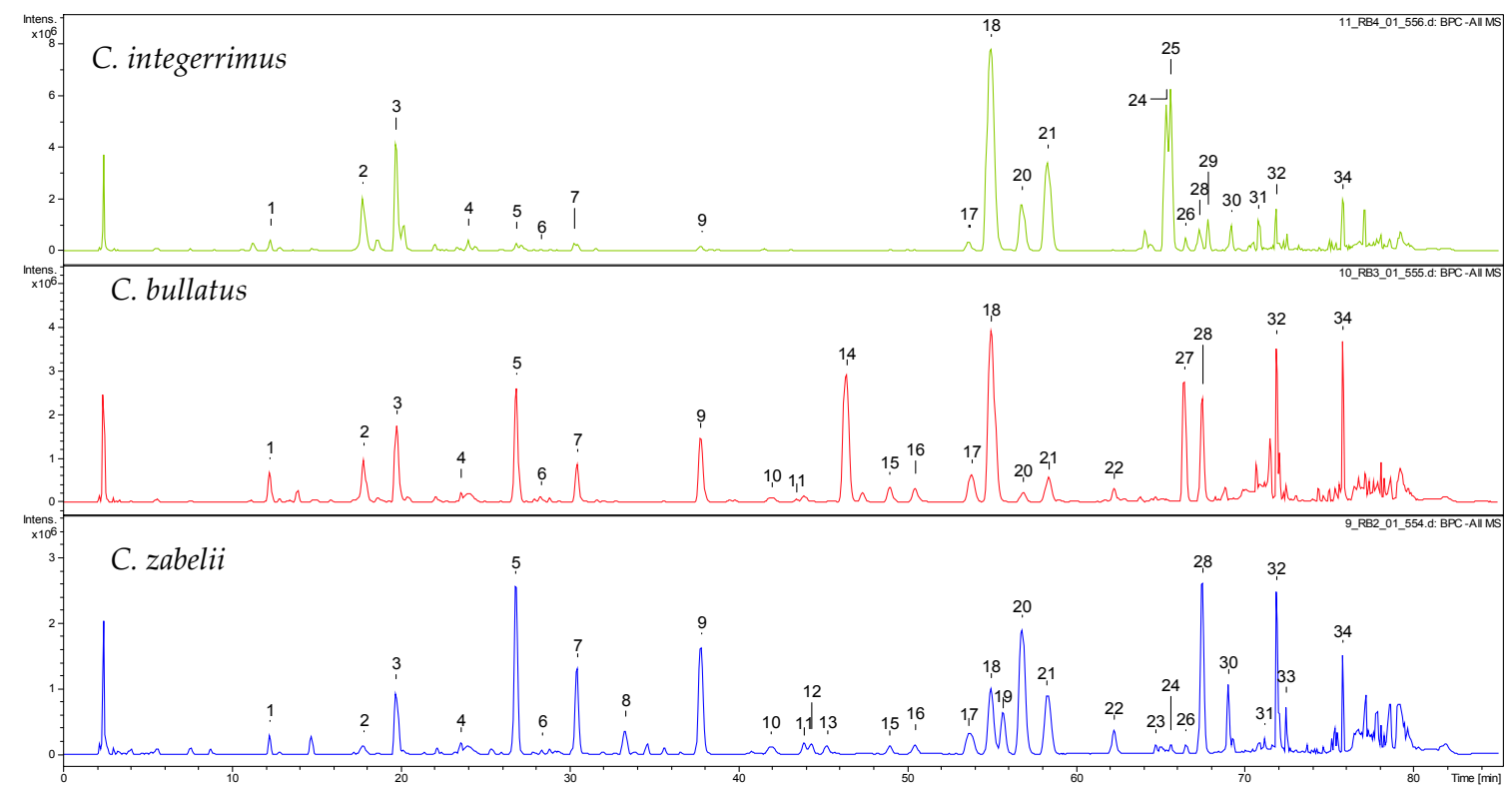

Figure 1. Representative total ion chromatograms (TIC) of the C. integerrimus, C. bullatus and C. zabelii leaf extracts recorded in the negative ion mode. The peak numbers of compounds refer to those used in Table 1. 
Table 1. UHPLC-PDA-ESI-QTOF-MS data of identified polyphenols in the Cotoneaster leaf extracts.

\begin{tabular}{|c|c|c|c|c|c|c|c|c|c|c|c|c|c|c|c|c|}
\hline No. ${ }^{a}$ & Compound & $\underset{(\mathrm{min})}{t_{R}}$ & $\mathrm{UV}(\mathrm{nm})$ & $\underset{m / z}{[\mathrm{M}-\mathrm{H}]^{-}}$ & 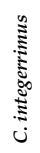 & 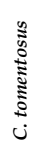 & 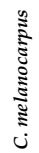 & 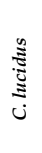 & 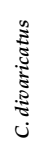 & 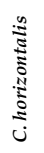 & 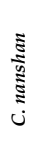 & 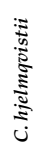 & 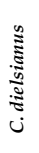 & 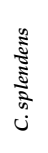 & 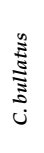 & 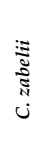 \\
\hline 1 & 3-O-caffeoylquinic acid (NCHA) b,c & 12.2 & 294,325 & 353.1 & + & + & + & + & + & + & + & + & + & + & + & + \\
\hline 2 & dicaffeoylquinic acid isomer $d$ & 17.8 & 295,325 & 515.1 & + & + & + & + & + & + & + & + & + & + & + & + \\
\hline 3 & 5-O-caffeoylquinic acid (CHA) b,c & 19.7 & 294,325 & 353.1 & + & + & + & + & + & + & + & + & + & + & + & + \\
\hline 4 & 4-O-caffeoylquinic acid (CCHA) b,c & 23.6 & 294,325 & 353.1 & + & + & + & + & + & + & + & + & + & + & + & + \\
\hline 5 & procyanidin dimer $\mathrm{B}-2 \mathrm{C}$ & 26.8 & 280 & 577.2 & + & + & + & + & + & + & + & + & + & + & + & + \\
\hline 6 & 5-p-coumaroylquinic acid b & 27.9 & 289,310 & 337.1 & + & + & + & + & + & + & + & + & + & + & + & + \\
\hline 7 & (-)-epicatechin C & 30.5 & 280 & 289.1 & + & + & + & + & + & + & + & + & & + & + & + \\
\hline 8 & caffeic acid derivative $\mathrm{d}$ & 33.3 & 290,328 & $613.1^{\mathrm{e}}$ & & + & + & & & & & + & & & & + \\
\hline 9 & procyanidin trimer $\mathrm{C}-1 \mathrm{c}$ & 37.8 & 280 & 865.2 & + & + & + & + & + & + & + & + & + & + & + & + \\
\hline 10 & procyanidin B-type tetramer $\mathrm{d}$ & 41.9 & 280 & 1153.1 & & & & + & + & + & + & + & + & + & + & + \\
\hline 11 & procyanidin B-type trimer $d$ & 43.9 & 280 & 865.2 & & & & + & + & & & + & & + & + & + \\
\hline 12 & quercetin $3-O-\beta$-glucoside-7-O- $\alpha$-rhamnoside ${ }^{c}$ & 44.3 & 265,350 & 609.2 & & & & & & + & & & & & & + \\
\hline 13 & procyanidin B-type tetramer $\mathrm{d}$ & 45.6 & 280 & 1153.2 & & & & + & & + & & + & & & & + \\
\hline 14 & quercetin $3-O-\beta-\left(2^{\prime \prime}-O-\beta\right.$-xylosyl)galactoside ${ }^{c}$ & 46.3 & 268,355 & 595.1 & & & & & & + & + & + & + & + & + & \\
\hline 15 & epicatechin derivative ${ }^{d}$ & 48.9 & 280 & 739.2 & & + & + & + & + & + & + & + & + & + & + & + \\
\hline 16 & epicatechin derivative $\mathrm{d}$ & 50.5 & 280 & 739.2 & & + & + & + & + & + & + & + & + & + & + & + \\
\hline 17 & quercetin rhamnoside-hexoside $\mathrm{d}$ & 53.7 & 265,350 & 609.1 & + & + & + & + & + & + & + & + & + & + & + & + \\
\hline 18 & hyperoside $\mathrm{c}^{\mathrm{C}}$ & 55.0 & 265,355 & 463.1 & + & + & + & + & + & + & + & + & + & + & + & + \\
\hline 19 & quercetin dirhamnoside $\mathrm{d}$ & 55.7 & 275,345 & 593.1 & & + & & & & + & & & & & & + \\
\hline 20 & rutin ${ }^{c}$ & 56.8 & 260,355 & 609.1 & + & + & + & + & + & + & + & + & + & + & + & + \\
\hline 21 & isoquercitrin $\mathrm{c}$ & 58.4 & 275,350 & 463.1 & + & + & + & + & + & + & + & + & + & + & + & + \\
\hline 22 & procyanidin B-type dimer $\mathrm{d}$ & 62.2 & 280 & 577.1 & & & & + & + & & & + & & + & + & + \\
\hline 23 & procyanidin B-type trimer $\mathrm{d}$ & 64.7 & 280 & 865.2 & & & & + & + & & & + & & + & & + \\
\hline 24 & quercetin hexoside derivative $\mathrm{d}$ & 65.4 & 256,355 & 505.1 & + & + & + & & + & & + & & & & & + \\
\hline 25 & quercetin hexoside derivative $\mathrm{d}$ & 65.6 & 256,355 & 505.1 & + & + & + & & & & + & & & & & \\
\hline 26 & kaempferol rhamnoside-hexoside $\mathrm{d}$ & 66.5 & 273,345 & 593.1 & + & + & + & + & + & + & & + & & + & & + \\
\hline 27 & quercetin rhamnoside-hexoside $\mathrm{d}$ & 66.6 & 276,350 & 609.1 & & + & + & + & + & + & & & + & + & + & \\
\hline 28 & quercitrin ${ }^{c}$ & 67.3 & 276,350 & 447.1 & + & + & + & + & + & + & & + & + & + & + & + \\
\hline 29 & dicaffeoylquinic acid isomer $\mathrm{d}$ & 67.8 & 285,325 & 515.1 & + & + & + & + & + & + & + & + & + & + & & \\
\hline 30 & quercetin hexoside derivative $\mathrm{d}$ & 69.2 & 255,355 & 505.1 & + & + & & & & & & & & & & + \\
\hline 31 & dicaffeoylquinic acid isomer ${ }^{d}$ & 70.9 & 286,325 & 515.1 & + & + & + & & + & + & + & + & + & + & & + \\
\hline 32 & unknown compound & 71.8 & 280 & 451.1 & + & + & + & + & + & + & + & + & + & + & + & + \\
\hline 33 & kaempferol rhamnoside-hexoside $\mathrm{d}$ & 72.5 & 275,345 & 593.1 & & + & & & & & & + & + & + & & + \\
\hline 34 & unknown compound & 75.8 & 316 & 487.3 & + & + & + & + & + & + & + & + & + & + & + & + \\
\hline
\end{tabular}

Compounds 5, 7, 9-11, 13, 15-16 and 22-23 with UV maxima at $280 \mathrm{~nm}$ were characterized as mono- and oligomeric proanthocyanidins. Compound 7 exhibited parent $[\mathbf{M}-\mathbf{H}]^{-}$ion at $m / z 289$ and by comparison with the reference compound it was identified as (-)-epicatechin, previously reported in C. nummularia, C. orbicularis and C. accuminaus $[16,19,23]$. Compounds 5 and 22 revealed pseudomolecular ions at $m / z 577$ and the secondary peaks at $m / z 451,425,407$ and 289 characteristic for procyanidin B-type dimers [31]. As confirmed by comparison with the authentic standard, compound 5 was identified as procyanidin B-2. In the case of compounds $\mathbf{9}, \mathbf{1 1}$, and $\mathbf{2 3}$, their pseudomolecular ions at $m / z 865$ yielding the fragments at $m / z 713,577,451,407$ and 289 indicated the presence of procyanidin B-type trimers [31]. By direct comparison with the reference standard, compound 9 was confirmed as procyanidin trimer C-1. Compounds $\mathbf{1 0}$ and 13, based on MS fragmentation of parent ions at $m / z 1153$ to characteristic peaks at $m / z 1027,863,575,407$ and 289, were assigned as procyanidin B-type tetramers. Compounds $\mathbf{1 5}$ and $\mathbf{1 6}$ were tentatively proposed to be (-)-epicatechin derivatives, because their $[\mathrm{M}-\mathrm{H}]^{-}$ions at $m / z 739$ yielded the fragments at $m / z 289$, characteristic for epicatechin, the dominant unit in the B-type oligomeric procyanidins of the analyzed Cotoneaster species. In consequence, in the group of proanthocyanidins, 10 individual compounds were identified with the predominant dimer B-2 and trimer C-1 detected in all analyzed Cotoneaster samples.

Compounds 12, 14, 17-21, 24-28, 30 and 33, based on the UV-Vis spectra with two maxima, first at 260-280 and second at 345-355 nm, were classified as flavonoids. All compounds in this group were found to be flavonoid mono- and diglycosides due to neutral losses in their MS spectra of sugar moieties ( -132 for pentose, -162 for hexose and -146 for rhamnose). Furthermore, the signals in the MS spectra, assignable to the aglycone moieties at $m / z 300$ or 285 suggested that all detected flavonoids are glycosides of quercetin or kaempferol. 
Compounds 18 and 21 with the pseudomolecular $[\mathrm{M}-\mathrm{H}]^{-}$ions at $m / z 463$ were identified with the authentic standards as hyperoside and isoquercitrin, respectively. These flavonoids were previously reported as constituents of $C$. melanocarpus and C. orbicularis [12,19]. Compound 28 revealed $[\mathrm{M}-\mathrm{H}]^{-}$ion at $m / z 447$ and after comparison with the standard was assigned as quercitrin, previously reported in C. thymaefolia [21]. Compounds 24-25 and 30, based on their pseudomolecular ions at $m / z 505$ which yielded fragments at $m / z 463$ and 300, were tentatively assigned as quercetin hexoside derivatives. Compound $\mathbf{1 4}$ as a flavonoid diglycoside, with the parent ion at $m / z 595$ revealing neutral loss of 132 and $162 \mathrm{amu}$ characteristic for pentose and hexose, respectively, was identified with the authentic standard as quercetin 3-O- $\left(2^{\prime \prime}-O-\beta-x y l o s y l\right)$ galactoside. Compounds 12, 17, 20 and 27 exhibited pseudomolecular ions at $m / z$ 609. By direct comparison with the reference standards, compounds 12 and 20 were identified as quercetin 3-O- $\beta$-glucoside-7-O- $\alpha$-rhamnoside and rutin, respectively. Among the latter compounds, only rutin was previously detected in C. melanocarpus, C. orbicularis and C. thymaefolia $[12,19,21]$. Compounds $\mathbf{1 7}$ and $\mathbf{2 7}$ were tentatively assigned to quercetin rhamnoside-hexoside due to the neutral losses of rhamnose (-146 amu) and hexose (-162 amu) and production of aglycone peaks at $m / z$ 300. Compounds 19, 26 and 33 with parent ions at $m / z 593$ were tentatively identified as quercetin or kaempferol diglycosides. Compound 19 was assigned as quercetin dirhamnoside due to the observed fragments ion at $m / z 447$ and the aglycone signal at $\mathrm{m} / \mathrm{z}$ 300. In the case of compounds 26 and 33, fragmentation of the parent ions led to the cleavage of rhamnose $(-146 \mathrm{amu})$ and hexose $(-162 \mathrm{amu})$ resulting in production of the aglycone peaks at $m / z$ 285. Thus, compounds $\mathbf{2 6}$ and 33 were proposed as kaempferol rhamnoside-hexosides. In all analyzed Cotoneaster species, flavonoids were mainly represented by hyperoside (18), isoquercitrin (21), rutin (20) and quercetin rhamnoside-hexoside (17).

\subsection{Quantitative Determination of Phenolics, Proanthocyanidins, Flavonoids and Chlorogenic Acid Isomers in the Cotoneaster Leaf Extracts}

Total phenolic content (TPC) of the Cotoneaster leaf samples was determined by the FC assay and expressed as Gallic acid equivalents (GAE). In this method, the reagent is formed from a mixture of phosphotungstic and phosphomolybdic acids, which after oxidation of the phenols were reduced to blue oxides of tungsten and molybdenum. Although the FC assay is widely used to estimate total phenolics in a sample matrix, it can be also useful as a nonspecific antioxidant assay, because its basic redox mechanism is similar to those occurring in antioxidant tests [32,33].

As shown in Table 2 and Figure 2a, the total phenolic content (TPC) in the Cotoneaster leaves varied from $5.2 \%$ to $15.4 \%$ GAE of the leaf dry weight $(\mathrm{dw})$, depending on the tested species, with the average value of $9.6 \%$ GAE. The highest TPC levels were observed for the leaf sample of $C$. bullatus, whereas C. melanocarpus and C. tomentosus contained the lowest amounts of phenolics. With the levels about or above $10 \%$ GAE, six samples may be classified as polyphenol-rich and especially promising for further studies of antioxidant activity. Within this group, the TPC values decreased in the order: C. bullatus $>$ C. zabelii $>$ C. hjelmqvistii $>$ C. divaricatus $>$ C. lucidus $>$ C. splendens.

According to the literature, the quantitative data regarding Cotoneaster polyphenols are limited only to a few studies on the dry extracts and indicate a large discrepancy in polyphenolic contents between the species [16,18]. According to Zengin et al. [16], different polarity extracts from the twigs of $C$. nummularia collected in Turkey contained total phenolics in the range $8.1 \%-26.6 \%$ GAE, with the highest level found for methanol and water extracts. On the other hand, as reported by Mohamed et al. [18], the TPC value of methanol extract from C. horizontalis branches cultivated in Egypt amounted only $1.4 \%$ GAE. It is thus clear, that the Cotoneaster leaves of Polish origin are particularly rich in polyphenols, whose contents of up to $15 \%$ GAE in dried plant materials are comparable or even higher than those observed for other polyphenol abundant Rosaceae leaves, i.e., Rosa canina (10.0\%-15.2\% GAE) [34], various Sorbus species (5.1\%-12.3\% GAE) [35], Aronia melanocarpa (13.9\% GAE) [36] and Ribes nigrum (3.2\%-4.4\% GAE) [37]. 
Table 2. Total phenolic (TPC), total proanthocyanidin (TPAC), and total flavonoid (TFC) contents in the Cotoneaster leaf extracts ${ }^{\mathrm{a}}$.

\begin{tabular}{|c|c|c|c|c|c|}
\hline \multirow{2}{*}{ No. } & \multirow{2}{*}{ Leaf Sample } & \multirow{2}{*}{ TPC (\% GAE) } & \multirow{2}{*}{ TPAC (\% CYE) } & \multicolumn{2}{|c|}{ TFC (\%) } \\
\hline & & & & QU & KA \\
\hline 1 & C. integerrimus & $8.74 \pm 0.38^{C}$ & $5.59 \pm 0.05^{\mathrm{A}}$ & $1.32 \pm 0.04^{\mathrm{H}}$ & $0.073 \pm 0.003^{G}$ \\
\hline 2 & C. tomentosus & $5.17 \pm 0.12^{\mathrm{A}}$ & $2.60 \pm 0.01^{\mathrm{D}}$ & $0.36 \pm 0.01^{\mathrm{B}}$ & $0.097 \pm 0.004^{\mathrm{H}}$ \\
\hline 3 & C. melanocarpus & $5.48 \pm 0.07^{\mathrm{A}}$ & $2.14 \pm 0.03^{C}$ & $0.26 \pm 0.01^{\mathrm{A}}$ & $0.025 \pm 0.001^{\mathrm{B}}$ \\
\hline 4 & C. lucidus & $10.68 \pm 0.10^{\mathrm{D}}$ & $6.34 \pm 0.12^{\mathrm{F}}$ & $0.40 \pm 0.01^{\mathrm{B}, \mathrm{C}}$ & $0.027 \pm 0.001 \mathrm{~B}, \mathrm{C}$ \\
\hline 5 & C. divaricatus & $11.97 \pm 0.07^{\mathrm{E}}$ & $9.08 \pm 0.04^{\mathrm{B}}$ & $0.70 \pm 0.03^{\mathrm{D}}$ & $0.049 \pm 0.001^{\mathrm{E}}$ \\
\hline 6 & C. horizontalis & $7.30 \pm 0.20^{B}$ & $5.36 \pm 0.04^{\mathrm{A}}$ & $0.27 \pm 0.01^{\mathrm{A}}$ & $0.127 \pm 0.003^{\mathrm{D}}$ \\
\hline 7 & C. nanshan & $8.43 \pm 0.17^{C}$ & $4.13 \pm 0.05^{\mathrm{E}}$ & $0.97 \pm 0.02 \mathrm{G}$ & nd \\
\hline 8 & C. hjelmqvistii & $12.49 \pm 0.41^{\mathrm{E}, \mathrm{F}}$ & $9.40 \pm 0.36^{\mathrm{B}}$ & $0.43 \pm 0.03^{C}$ & $0.035 \pm 0.001^{C}$ \\
\hline 9 & C. dielsianus & $6.99 \pm 0.09^{\mathrm{B}}$ & $5.69 \pm 0.05^{\mathrm{A}}$ & $0.52 \pm 0.02 \mathrm{E}$ & $0.259 \pm 0.006^{\mathrm{I}}$ \\
\hline 10 & C. splendens & $9.92 \pm 0.33^{\mathrm{D}}$ & $9.13 \pm 0.12^{\mathrm{B}}$ & $0.73 \pm 0.02^{\mathrm{D}}$ & $0.126 \pm 0.005^{\mathrm{D}}$ \\
\hline 11 & C. bullatus & $15.43 \pm 0.51^{G}$ & $14.98 \pm 0.08^{\mathrm{H}}$ & $0.61 \pm 0.01^{\mathrm{F}}$ & nd \\
\hline 12 & C. zabelii & $12.94 \pm 0.28^{\mathrm{F}}$ & $10.86 \pm 0.09^{\mathrm{G}}$ & $0.28 \pm 0.01^{\mathrm{A}}$ & $0.063 \pm 0.001^{\mathrm{F}}$ \\
\hline
\end{tabular}

a All values are presented as the means \pm standard deviation (SD) calculated per $\mathrm{dw}$ of the plant material $(n=3 \times 5 \times 1)$; different capital letters within the same row indicate significant differences at $p<0.05$ by Tukey's test; TPC, total phenolic content, expressed as Gallic acid equivalents (GAE); TPAC, total proanthocyanidin content, expressed as cyanidin chloride equivalents (CYE); TFC, total flavonoid content, quantified by HPLC; QU, quercetin; KA, kaempferol.

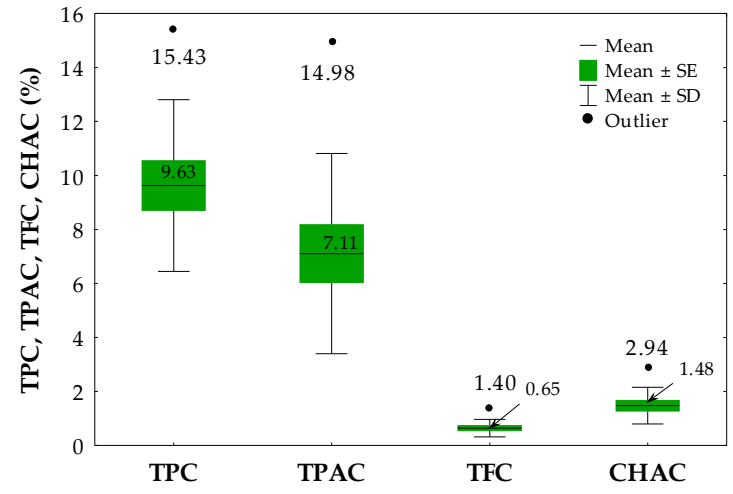

(a)

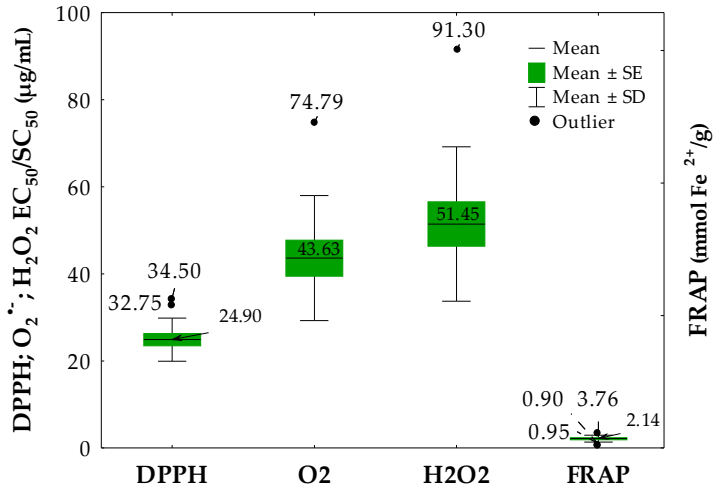

(b)

Figure 2. Box-whisker plot analysis of: (a) total contents of phenolics (TPC), proanthocyanidins (TPAC) flavonoids (TFC) and chlorogenic acid isomers (CHAC); and (b) antioxidant and reducing activity tested by SET and HAT-type methods in the Cotoneaster leaf samples. Mean values \pm standard errors (SE) and standard deviation (SD).

It is obvious, that the total phenolic level as measured by FC method does not give a full picture of the quality and quantity of the phenolic compounds in the matrix. There may be some interferences resulting in over- or underestimation and arising from non-phenolic reducing constituents, e.g., sugars, aromatic amines or ascorbic acid, as well as from differences in molecular structures and reactivity between original plant polyphenols and gallic acid as a calibrating standard [34]. Thus, to better characterize the phenolic profile of the Cotoneaster leaves, complementary assays of their total proanthocyanidins (TPAC), chlorogenic acid isomers (CHAC) and flavonoids (TFC) were conducted. The TPAC was determined by spectrophotometric $n$-butanol $/ \mathrm{HCl}$ method and expressed in cyanidin chloride equivalents (CYE). The CHAC as a sum of monocaffeoylquinic acid isomers (NCHA, CHA and (CHA) and TFC after acid hydrolysis as a sum of flavonoid aglycones were quantified using RP-HPLC-PDA methods. As shown in Tables 2 and 3 and Figure 3a, majority of the tested samples exhibited relatively high levels of total proanthocyanidins ranging from $2.6 \%$ to $15.0 \%$ CYE dw, with the average value of $7.1 \%$ CYE. The highest TPAC contents were noted for C. bullatus leaves $(15.0 \%$ 
CYE), followed by C. zabelii (10.9\% CYE), C. hjelmqvistii (9.4\% CYE), C. splendens and C. divaricatus (for each of about $9.1 \%$ CYE). It is noteworthy, that the content of proanthocyanidins in all samples tested had a strong impact on their total phenolic level, which is reflected by high and statistically significant correlation found between these values $\left(|r|\left(R^{2}\right)=0.9419(0.8872), p<0.001\right)$. With the TPAC levels constituting $39 \%-97 \%$ of the TPC values, proanthocyanidins appear to be the dominant phenolic constituents of the tested leaves. The content of caffeoylquinic acid isomers varied among the species $(0.69 \%-2.93 \% \mathrm{dw})$, with the highest amount found for C. hjelmqvistii and C. divaricatus $(2.9 \%$ and $2.1 \%$, respectively). The chlorogenic acid (CHA) was the dominant isomer in all tested samples, and its level constituted $73.3 \%-92.1 \%$ of the sum of three quantified isomers. The highest contents of two other isomers were found in the C. divaricatus sample, with the levels of $0.33 \%$ for NCHA and $0.10 \%$ for CCHA. Flavonoids as the third analyzed group also revealed high quantitative variability with the TFC levels ranging from $0.3 \%$ to $1.4 \% \mathrm{dw}$, depending on the sample. The leaves of $C$. integerrimus exhibited the highest TFC content and those of C. melanocarpus the lowest. As regards individual aglycones, quercetin and kaempferol were detected in majority of the Cotoneaster leaf hydrolyzates (Table 2). All analyzed samples were devoid of other flavonoid aglycones i.e., apigenin and luteolin reported earlier $[16,19,21,23]$ for the twigs, leaves and roots of C. nummularia, C. orbicularis, C. thymaefolia and C. acuminatus. Out of flavonoids detected in the assayed samples, the most abundant aglycone was quercetin with the levels $(0.26 \%-1.32 \% \mathrm{dw})$ constituting $68 \%-100 \%$ of the sum of both quantified aglycones. In ten samples, quercetin was accompanied by kaempferol, whose content reached up to $0.26 \% \mathrm{dw}$, whereas, in the samples of C. nanshan and C. bullatus, the quercetin at the level of $0.97 \%$ and $0.61 \%$, respectively, was the single flavonoid found.

Table 3. Total content of chlorogenic acid isomers (CHAC) in the Cotoneaster leaf extracts ${ }^{\mathrm{a}}$.

\begin{tabular}{ccccc}
\hline & & \multicolumn{3}{c}{ CHAC (\%) } \\
\cline { 3 - 5 } No. & Leaf Sample & NCHA & CHA & CCHA \\
\hline $\mathbf{1}$ & C. integerrimus & $0.125 \pm 0.001^{\mathrm{A}}$ & $1.58 \pm 0.01^{\mathrm{B}}$ & $0.058 \pm 0.001^{\mathrm{A}}$ \\
$\mathbf{2}$ & C. tomentosus & $0.069 \pm 0.003^{\mathrm{C}, \mathrm{D}}$ & $0.68 \pm 0.03^{\mathrm{A}}$ & $0.037 \pm 0.002^{\mathrm{B}}$ \\
$\mathbf{3}$ & C. melanocarpus & $0.081 \pm 0.002^{\mathrm{D}}$ & $0.65 \pm 0.02^{\mathrm{A}}$ & $0.031^{\mathrm{B}} 0.001^{\mathrm{E}}$ \\
$\mathbf{4}$ & C. lucidus & $0.170 \pm 0.008^{\mathrm{B}}$ & $1.19 \pm 0.05^{\mathrm{E}}$ & $0.063 \pm 0.002^{\mathrm{C}, \mathrm{D}}$ \\
$\mathbf{5}$ & C. divaricatus & $0.327 \pm 0.005^{\mathrm{E}}$ & $1.70 \pm 0.04^{\mathrm{C}}$ & $0.099 \pm 0.004^{\mathrm{F}}$ \\
$\mathbf{6}$ & C. horizontalis & $0.108 \pm 0.003^{\mathrm{A}}$ & $1.57 \pm 0.04^{\mathrm{B}}$ & $0.047 \pm 0.001^{\mathrm{A}}$ \\
$\mathbf{7}$ & C. nanshan & $0.116 \pm 0.001^{\mathrm{A}}$ & $1.75 \pm 0.01^{\mathrm{C}}$ & $0.053 \pm 0.001^{\mathrm{A}}$ \\
$\mathbf{8}$ & C. hjelmqvistii & $0.166 \pm 0.005^{\mathrm{B}}$ & $2.70 \pm 0.01^{\mathrm{G}}$ & $0.067 \pm 0.003^{\mathrm{C}}$ \\
$\mathbf{9}$ & C. dielsianus & $0.103 \pm 0.003^{\mathrm{A}}$ & $0.94 \pm 0.02^{\mathrm{D}}$ & $0.039 \pm 0.001^{\mathrm{B}}$ \\
$\mathbf{1 0}$ & C. splendens & $0.167 \pm 0.008^{\mathrm{B}}$ & $1.39 \pm 0.06^{\mathrm{F}}$ & $0.040 \pm 0.002^{\mathrm{B}}$ \\
$\mathbf{1 1}$ & C. bullatus & $0.161 \pm 0.003^{\mathrm{B}}$ & $0.63 \pm 0.01^{\mathrm{A}}$ & $0.068 \pm 0.001^{\mathrm{C}}$ \\
$\mathbf{1 2}$ & C. zabelii & $0.066 \pm 0.001^{\mathrm{C}}$ & $0.57 \pm 0.01^{\mathrm{A}}$ & $0.051 \pm 0.001^{\mathrm{A}}$ \\
\hline
\end{tabular}

a All values are presented as the means + SD calculated per $\mathrm{dw}$ of the plant material $(n=3 \times 5 \times 1)$; different capital letters within the same row indicate significant differences at $p<0.05$ by Tukey's test; CHAC, content of chlorogenic acid isomers quantified by HPLC; NCHA, neochlorogenic acid; CHA, chlorogenic acid and CCHA, cryptochlorogenic acid. 

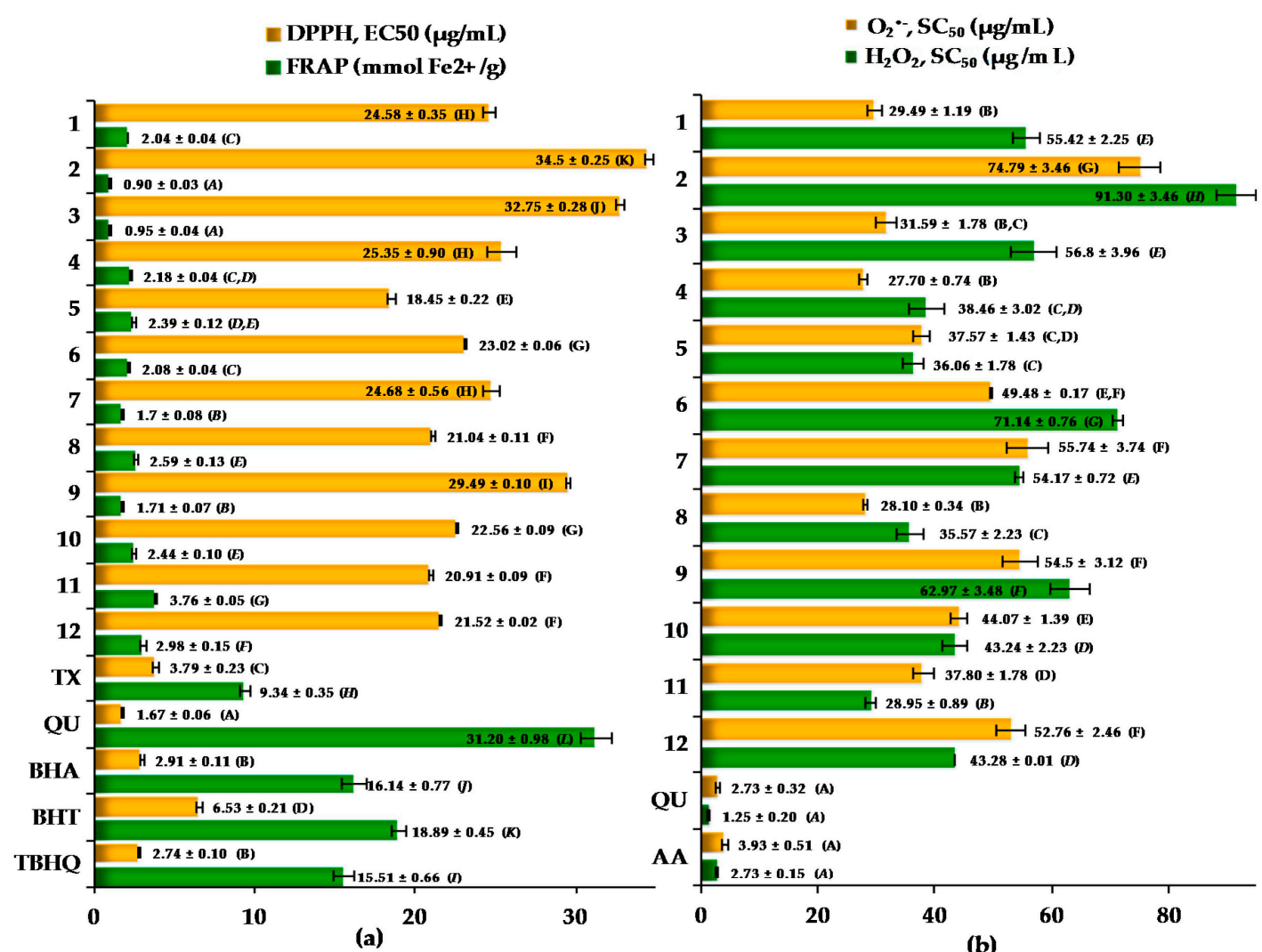

Figure 3. Antioxidant activity of the Cotoneaster leaf extracts and standard antioxidants in: (a) the DPPH and FRAP tests; and (b) $\mathrm{O}_{2}{ }^{\bullet-}$ and $\mathrm{H}_{2} \mathrm{O}_{2}$ scavenging tests. Results are presented as the mean values $\pm \mathrm{SD}(n=3)$; for each activity parameter different capital letters (A-G and $\mathrm{A}-\mathrm{L})$ indicate significant differences at $p<0.05$ by Tukey's test; scavenging ability $\left(\mathrm{EC}_{50}\right.$ and $\mathrm{SC}_{50}$ ), the amount of the plant samples or the standards required for $50 \%$ reduction of initial ROS concentration; FRAP, ferric reducing antioxidant power expressed in $\mathrm{mmol} \mathrm{Fe}^{2+}$ per $\mathrm{g}$ of the dry leaves or the reference compounds; for the species codification see Table 1 ; reference standards: TX, Trolox ${ }^{\circledR}$; QU, quercetin; AA, ascorbic acid; BHA, butylated hydroxyanisole; BHT, 2,6-di-tert-butyl-4-methylphenol; TBHQ, tert-butyl-hydroquinone.

\subsection{Antioxidant Activity of the Cotoneaster Leaf Extracts}

A variety of antioxidant assays based on hydrogen atom transfer (HAT) and/or single electron transfer (SET) reaction mechanisms have been widely employed for quantification of antioxidant capacity of phenolic samples, but there is no universal assay that can accurately reflect all the antioxidants in a complex system [32]. Therefore, to evaluate the total antioxidant capacity of plant matrix it is necessary to diversify the tests. In this study, four in vitro assays, namely the two widely used SET-based methods: the 2,2-diphenyl-1-picrylhydrazyl (DPPH) free radical scavenging and the ferric reducing antioxidant power (FRAP) tests as well as two HAT-based methods for scavenging superoxide anion $\left(\mathrm{O}_{2}{ }^{\bullet-}\right)$ and hydrogen peroxide $\left(\mathrm{H}_{2} \mathrm{O}_{2}\right)$ were employed to evaluate the antioxidant properties of the Cotoneaster leaf extracts. In all applied tests, on the basis of the chemical reaction involved, the extract capability was evaluated for free radical scavenging (DPPH, $\mathrm{O}_{2}{ }^{\bullet-}$ ), for quenching non-radical $\mathrm{ROS}\left(\mathrm{H}_{2} \mathrm{O}_{2}\right)$ as well as for reducing metal ions $\left(\mathrm{Fe}^{3+}\right)$.

As presented in Figures $2 \mathrm{~b}$ and $3 \mathrm{a}, \mathrm{b}$, activity of the analyzed Cotoneaster leaf extracts increased in a concentration-dependent manner with different range of efficiencies depending on the test. In the DPPH assay, the $\mathrm{EC}_{50}$ values of all tested samples varied in a narrow range of $18.5-34.5 \mu \mathrm{g} / \mathrm{mL}$. The highest activity was noted for leaf extract of $C$. divaricatus followed by that of $C$. bullatus, $C$. hjelmqvistii and C. zabelii. In the FRAP test, the range of FRAP values for the tested samples was relatively wider 
(0.9-3.8 $\mathrm{mmol} \mathrm{Fe}{ }^{2+} / \mathrm{g}$ ), and the highest activity was found for C. bullatus, C. zabelii and C. hjelmqvistii samples. In the $\mathrm{H}_{2} \mathrm{O}_{2}$ test, the differences in the $\mathrm{SC}_{50}$ values between the samples were also pronounced $(29.0-91.3 \mu \mathrm{g} / \mathrm{mL})$ and the highest activity parameters were obtained for the samples of C. bullatus, C. hjelmqvistii and C. divaricatus. It is of note that the leaves of C. bullatus, C. zabelii, C. divaricatus and C. hjelmqvistii, found in the present study as the richest sources of polyphenols, also displayed the highest antioxidant and reducing activities in aforementioned tests.

In the case of the $\mathrm{O}_{2}{ }^{\bullet-}$ test, the $\mathrm{SC}_{50}$ values also varied in wide range of $27.7-74.8 \mu \mathrm{g} / \mathrm{mL}$ but a different order of the antiradical efficiencies was observed among the samples. The leaves of C. lucidus, C. hjelmqvistii and C. integerrimus displayed higher activity (mean values of $\mathrm{SC}_{50}=28.4 \mu \mathrm{g} / \mathrm{mL}$ ) in comparison to the leaf samples of C. divaricatus $\left(\mathrm{SC}_{50}=37.6 \mu \mathrm{g} / \mathrm{mL}\right)$, C. bullatus $\left(\mathrm{SC}_{50}=37.8 \mu \mathrm{g} / \mathrm{mL}\right)$ and C. zabelii $\left(\mathrm{SC}_{50}=52.8 \mu \mathrm{g} / \mathrm{mL}\right)$, for which the highest capacity was observed in the DPPH, FRAP and $\mathrm{H}_{2} \mathrm{O}_{2}$ tests. The relatively high $\mathrm{O}_{2}{ }^{\bullet-}$ scavenging activity of the $C$. integerrimus leaves, connected with only moderate TPC level as compared to C. lucidus and C. hjelmqvistii samples, may be influenced by the considerably higher flavonoid content $(1.4 \% \mathrm{dw})$. It is known, that flavonoids as hydrogen atom donators are able to effectively reduce highly oxidizing radicals such as superoxide, peroxyl, alkoxyl, and hydroxyl radicals [38], which was also proven in the present study for the reference quercetin $\left(\mathrm{SC}_{50}=2.7 \mu \mathrm{g} / \mathrm{mL}\right)$.

The literature data on the antioxidant activity of Cotoneaster species are scarce and present highly variable results $[12,16,17]$. In the DPPH scavenging test, the dry ethanol extract from $C$. horizontalis branches was characterized by the $\mathrm{EC}_{50}$ value of $19.5 \mu \mathrm{g} / \mathrm{mL}$ [17]. On the other hand, the dry methanol extracts of C. nummularia twigs and C. melanocarpus leaves exhibited notably lower activity, with the $\mathrm{EC}_{50}$ values of 104 and $106 \mu \mathrm{g} / \mathrm{mL}$, respectively [12,16]. As each study focuses only on one species at a time, it is difficult to draw any valid conclusions about the reasons of this variability. Our research is the first to compare larger number of Cotoneaster species in terms of their antioxidant capacity in one study design and therefore provides better insight into the nature and extent of the activity of the genus.

As presented in the Table 4, the antioxidant activity of all Cotoneaster leaf samples was strongly dependent on the total polyphenol (TPC) and proanthocyanidin (TPAC) contents, which is reflected in significant linear correlations $(p<0.01)$ between the TPC, TPAC values and the results of DPPH, FRAP and $\mathrm{H}_{2} \mathrm{O}_{2}$ reduction tests. On the other hand, no such effect was observed in case of TFC and CHAC which was caused probably by the relatively lower level of flavonoids and chlorogenic acid isomers in comparison to proanthocyanidins. The significant correlations were also found between the results of three aforementioned antioxidant activity assays, that suggests that the Cotoneaster extracts could be considered universal antioxidants utilizing both basic reaction mechanisms and acting as direct ROS quenchers as well as reducing agents. Contrarily, the results of $\mathrm{O}_{2}{ }^{\bullet-}$ scavenging assay did not correlate neither with quantitative findings nor with the activity of the samples in the SET-type tests performed. Significant correlation was found only with the results of $\mathrm{H}_{2} \mathrm{O}_{2}$ quenching test, utilizing HAT-type mechanism. This phenomenon could be affected by non-phenolic constituents, which could co-occur in the Cotoneaster extracts. However, a more detailed study addressing the chemical nature of these compounds and their presence in the Cotoneaster samples is required.

Aside from the $\mathrm{O}_{2}{ }^{\bullet-}$ scavenging, significant, linear relationships existing between antioxidant capacity parameters and phenolic contents, suggests that polyphenols are important determinants of the SET- and HAT-type antioxidant activity of the tested Cotoneaster extracts. Moreover, given the more detailed quantitative analysis and the respective correlation results, proanthocyanidins seem to be the major contributors to the observed capacities. As was proven in numerous in vitro systems [39], the antioxidant activity of this group of compounds is largely dependent on their molecular structure, particularly the molecular weight expressed as degree of polymerization (DP). It was demonstrated, that proanthocyanidin oligomers characterized by DP $<10$ are especially effective ROS/RNS scavengers, with the antioxidant power greater than that of vitamins $C$ and $E$ [40]. Considering the high extraction efficiency of hydromethanolic solutions towards small proanthocyanidin oligomers [41], 
it can be safely assumed that the proanthocyanidin fraction of the investigated Cotoneaster extracts is dominated by this type of compounds. Proanthocyanidins including B-type dimers, trimers and tetramers were indeed identified in the extracts by UHPLC-QTOF-MS (Table 1). Among highly valued plant materials, characterized by especially high content of low molecular proanthocyanidin oligomers are seeds of Vitis vinifera [41]. Broadly acknowledged antioxidant activity of proanthocyanidin-rich grape seed extract, reflected in strong inhibition of oxidation of lipid and low density lipoproteins, is at the heart of its many health benefits, including cardioprotective and anti-atherosclerotic effect [41,42]. Thus, other sources of this valuable group of metabolites such as investigated Cotoneaster leaves definitely deserve attention and further studies.

Table 4. Correlation $(r)$ and determination $\left(R^{2}\right)$ coefficients for linear relationships between antioxidant capacities and phenolic contents of the Cotoneaster leaf extracts ${ }^{\mathrm{a}, \mathrm{b}}$.

\begin{tabular}{|c|c|c|c|c|}
\hline$r\left(R^{2}\right)$ & DPPH EC ${ }_{50}(\mu \mathrm{g} / \mathrm{mL})$ & FRAP $\left(\mathrm{mmolFe}^{2+} / \mathrm{g}\right)$ & $\mathrm{O}_{2} \bullet-\mathrm{SC}_{50}(\mu \mathrm{g} / \mathrm{mL})$ & $\mathrm{H}_{2} \mathrm{O}_{2} \mathrm{SC}_{50}(\mu \mathrm{g} / \mathrm{mL})$ \\
\hline TPC (\% GAE) & $-0.8298(0.6885) *$ & $0.9491(0.9008) *$ & $-0.4227(0.1787)$ & $-0.8676(0.7528) *$ \\
\hline TPAC (\% CYE) & $-0.7706(0.5938)$ ** & $0.9719(0.9447) *$ & $-0.2854(0.0815)$ & $-0.7639(0.5836)^{* *}$ \\
\hline TFC (\%; QU + KA) & $-0.1907(0.0364)$ & $0.0355(0.0013)$ & $-0.0976(0.0095)$ & $-0.0529(0.0028)$ \\
\hline$(\% ; \mathrm{NCHA}+\mathrm{CHA}+\mathrm{CCHA})$ & $-0.5366(0.2879)$ & $0.1392(0.0194)$ & $-0.4062(0.1650)$ & $-0.3148(0.0991)$ \\
\hline DPPH EC ${ }_{50}(\mu \mathrm{g} / \mathrm{mL})$ & - & $-0.8364(0.6996) *$ & $0.4218(0.1779)$ & $0.7580(0.5746)^{* *}$ \\
\hline FRAP $\left(\mathrm{mmol} \mathrm{Fe}^{2+} / \mathrm{g}\right)$ & $-0.8364(0.6996)$ * & - & $-0.3490(0.1218)$ & $-0.7746(0.6000) * *$ \\
\hline $\mathrm{O}_{2}{ }^{\bullet-} \mathrm{SC}_{50}(\mu \mathrm{g} / \mathrm{mL})$ & $0.4218(0.1779)$ & $-0.3490(0.1218)$ & - & $0.7127(0.5079) * *$ \\
\hline $\mathrm{H}_{2} \mathrm{O}_{2} \mathrm{SC}_{50}(\mu \mathrm{g} / \mathrm{mL})$ & $0.7580(0.5746)^{* *}$ & $-0.7746(0.6000)^{* *}$ & $0.7127(0.5079)^{* *}$ & - \\
\hline
\end{tabular}

\subsection{Hierarchical Cluster Analysis of the Phytochemical and Activity Data}

An agglomerative hierarchical cluster analysis (HCA) was performed for all experimental data, taking the Euclidean distance as metric and the complete linkage method as an amalgamation rule.

As shown in Figure 4, the analyzed Cotoneaster leaves were divided into three distinct clusters (CL-1-CL-3), which correspond to three diverse levels of their phytochemical and antioxidant capacities. In the CL-1, the six leaf samples of C. zabelii, C. splendens, C. bullatus, C. divaricatus, C. hjelmqvistii and C. lucidus were associated with the highest content of polyphenols (the mean TPC of $12.2 \% \pm 1.9 \%$ GAE) and proanthocyanidins (the average TPAC of 10.0\% $\pm 2.9 \% \mathrm{CYE}$ ) as well as high antioxidant activity as reported in Figure 3. The cluster CL-2 with five samples of C. dielsianus, C. nanshan, C. horizontalis, C. melanocarpus and $C$. integerrimus was characterized by almost twice lower levels of polyphenols (the mean TPC of $7.4 \% \pm 1.3 \%$ GAE) and proanthocyanidins (the average TPAC of $4.6 \% \pm 1.5 \%$ CYE) and also the significantly weaker antioxidant potential in comparison to CL-1. The CL-3 includes only one species of $C$. tomentosus, due to its significantly worse quality parameters than observed for the other samples, both in the phenolic content and antioxidant ability.

In order to more thoroughly assess the impact of phenolics on the antioxidant properties of the most valued samples grouped in the cluster CL-1, their average $\mathrm{EC}_{50}$ value $(21.6 \mu \mathrm{g}$ of the leaf dry weight $/ \mathrm{mL}$ ) for the DPPH test was recalculated to the phenolic effective concentration $\mathrm{PEC}_{50}$ with the use of the respective TPC levels. The obtained PEC $_{50}$ value of $2.64 \mu \mathrm{g}$ of the phenolics $/ \mathrm{mL}$ was comparable with that measured (Figure 3) for the positive control of Trolox $\left(\mathrm{EC}_{50}=3.79 \mu \mathrm{g} / \mathrm{mL}\right)$ and the reference synthetic antioxidants such as BHA $\left(\mathrm{EC}_{50}=2.91 \mu \mathrm{g} / \mathrm{mL}\right)$ and TBHQ $\left(\mathrm{EC}_{50}=2.74 \mu \mathrm{g} / \mathrm{mL}\right)$ widely used in food and cosmetic industry. Based on the above results, the six Cotoneaster samples (cluster CL-1) would be recognized as promising candidates for further in vitro and in vivo studies of antioxidant protection with great potential for the use as easily accessible, cost-effective and potentially non-toxic antioxidant agents. 


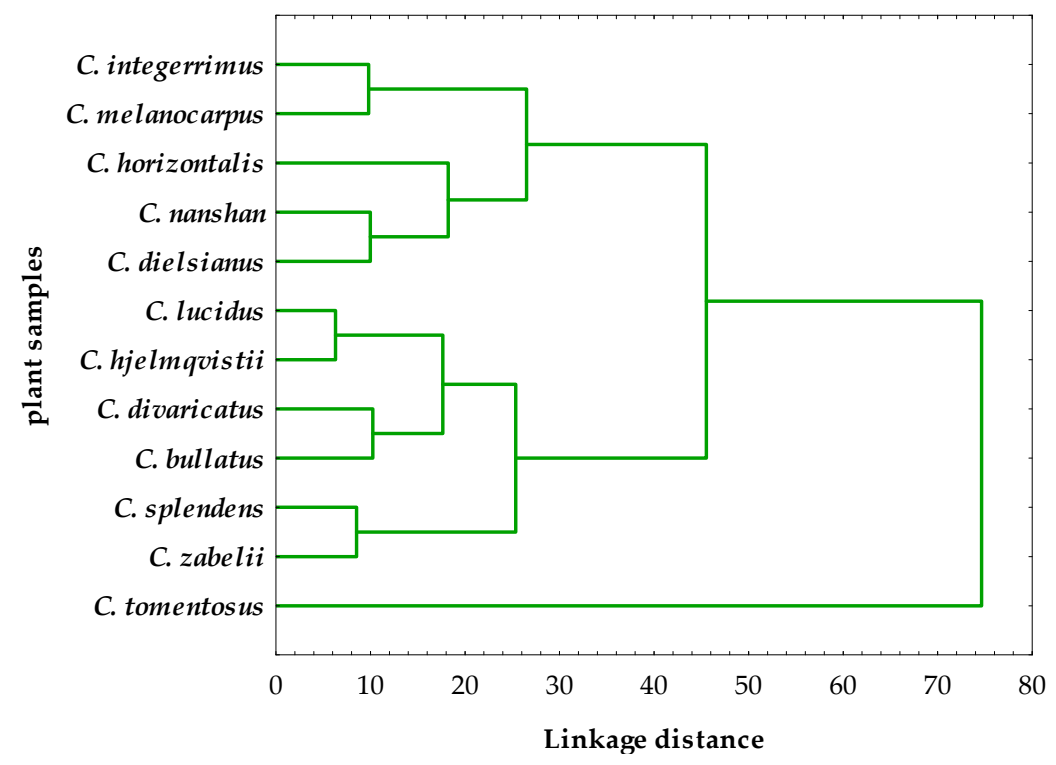

Figure 4. Hierarchical cluster analysis with all variables obtained for the Cotoneaster leaves using the complete linkage method and Euclidean squared distance.

\section{Materials and Methods}

\subsection{Plant Material}

Leaf samples of twelve selected Cotoneaster Medik. species were collected and authenticated in September/October 2012, in the Botanical Garden $\left(51^{\circ} 45^{\prime} \mathrm{N} 19^{\circ} 24^{\prime} \mathrm{E}\right.$ ) in Lodz (Poland) or in the Arboretum $\left(51^{\circ} 49^{\prime} \mathrm{N} 19^{\circ} 53^{\prime} \mathrm{E}\right)$, Forestry Experimental Station of Warsaw University of Life Sciences (SGGW) in Rogow (Poland). The list of the species employed, their collection sites and herbarium codes are given in Table 5. The voucher specimens were deposited in the Herbarium of the Department of Pharmacognosy, Medical University of Lodz (Poland). After harvest, the raw materials were air-dried under normal conditions, powdered with an electric grinder, sieved through a $0.315 \mathrm{~mm}$ sieve, and stored in airtight containers until use.

Table 5. Herbarium codes and collection sites of the analyzed Cotoneaster Medik. species.

\begin{tabular}{|c|c|c|c|}
\hline No. & Species & Herbarium Code & Collection Site \\
\hline 1 & \multirow{4}{*}{$\begin{array}{l}\text { C. integerrimus Medik. } \\
\text { C. tomentosus Lindl. } \\
\text { C. melanocarpus Lodd. ex. } \\
\text { C.K. Schneid. } \\
\text { C. lucidus Schltdl. }\end{array}$} & $\mathrm{KFG} / 12 / \mathrm{CIN}$ & \multirow{4}{*}{$\begin{array}{l}\text { Forestry Experimental } \\
\text { Station of Warsaw } \\
\text { University of Life } \\
\text { Sciences (Rogow, Poland) }\end{array}$} \\
\hline 2 & & KFG/12/CTM & \\
\hline 3 & & KFG/12/CMA & \\
\hline 4 & & KFG/12/CLC & \\
\hline 5 & $\begin{array}{l}\text { C. divaricatus Rehder et } \\
\text { E.H. Wilson }\end{array}$ & $\mathrm{KFG} / 12 / \mathrm{CDV}$ & \multirow{8}{*}{$\begin{array}{l}\text { Botanical Garden } \\
\text { (Lodz, Poland) }\end{array}$} \\
\hline 6 & C. horizontalis Decne. & KFG/12/CHR & \\
\hline 7 & C. nanshan Mottet & $\mathrm{KFG} / 12 / \mathrm{CNA}$ & \\
\hline 8 & $\begin{array}{c}\text { C. hjelmquistii Flinck et B. } \\
\text { Hylmö }\end{array}$ & $\mathrm{KFG} / 12 / \mathrm{CHQ}$ & \\
\hline 9 & C. dielsianus E. Pritz. & $\mathrm{KFG} / 12 / \mathrm{CDL}$ & \\
\hline 10 & $\begin{array}{l}\text { C. splendens Flinck et B. } \\
\text { Hylmö }\end{array}$ & $\mathrm{KFG} / 12 / \mathrm{CSP}$ & \\
\hline 11 & C. bullatus Bois & KFG/12/CBL & \\
\hline 12 & C. zabelii C.K. Schneid & $\mathrm{KFG/12/CZB}$ & \\
\hline
\end{tabular}




\subsection{General}

HPLC grade purity reagents and standards such as 2,2-diphenyl-1-picrylhydrazyl (DPPH), 2,4,6-tris-(2-pyridyl)-s-triazine (TPTZ), luminol, nitrobluetetrazolium, xanthine, xanthine oxidase, hydrogen peroxide; horseradish peroxidase, $( \pm$ )-6-hydroxy-2,2,7,8-tetramethylchroman-2-carboxylic acid (Trolox $\left.{ }^{\circledR}, \mathrm{TX}\right)$, ascorbic acid (AA), quercetin dihydrate (QU), kaempferol (KA), Gallic acid monohydrate (GA), cyanidin chloride (CY), chlorogenic acid (CHA), hyperoside (quercetin 3-O- $\beta$-D-galactopyranoside), isoquercitrin (quercetin 3-O- $\beta$-D-glucopyranoside), procyanidins B-2 and C-1, (-)-epicatechin were purchased from Sigma-Aldrich (Seelze, Germany/St. Louis, MO, USA). The analytical grade antioxidant standards such as butylated hydroxyanisole (BHA), 2,6-di-tert-butyl-4-methylphenol (BHT) and tert-butylhydroquinone (TBHQ) were obtained from the same supplier. The qualitative standards of 3-O-caffeoylquinic acid (NCHA) and 4-O-caffeoylquinic acid (CCHA) were prepared by isomerization of CHA as described previously [43]. The standards of rutin, quercetin 3-O-(2 $2^{\prime \prime}-O-\beta$-xylosyl)galactoside, quercetin $3-O-\beta$-glucoside-7-O- $\alpha$-rhamnoside and quercitrin (quercetin 3-O- $\beta$-rhamnoside) were previously isolated in our laboratory with at least $95 \%$ HPLC purity. HPLC grade solvents, methanol (MeOH) and orto-phosphoric acid $\left(\mathrm{H}_{3} \mathrm{PO}_{4}\right)$ used for HPLC analyses were from Avantor Performance Materials (Gliwice, Poland). All other chemicals and solvents were of analytical grade and supplied by Avantor PM (Gliwice, Poland).

For nonenzymatic spectrophotometric tests, absorbance was measured using a Lambda 25 spectrophotometer (Perkin-Elmer, Walthman, MA, USA), in $10 \mathrm{~mm}$ quartz cuvettes. The samples for the FRAP assay were incubated in a constant temperature using a BD 23 incubator (Binder, Tuttlingen, Germany). Enzymatic tests were performed in 96-well plates and monitored using a microplate reader, Synergy 4 (BioTek, Vinooski, VT, USA).

\subsection{Extraction and Hydrolysis Procedures}

The accurately weighed samples (100 or $500 \mathrm{mg}$ ) were first defatted by pre-extraction with chloroform ( $20 \mathrm{~mL}, 15 \mathrm{~min}$, the chloroform extracts was discarded) and then refluxed for $30 \mathrm{~min}$ with $30 \mathrm{~mL}$ of $70 \%(v / v)$ aqueous methanol. After filtering the extract, the pellet was extracted twice for $15 \mathrm{~min}$ with $20 \mathrm{~mL}$ of the same solvent. The combined filtrates were diluted with the solvent to $100 \mathrm{~mL}$. Each sample was extracted in triplicate to give crude fluid extracts (CE), which were tested for their total phenolic (TPC), proanthocyanidin (TPAC) and chlorogenic acid isomer (CHAC) contents as well as antioxidant activity. For qualitative UHPLC analyses, the prepared crude extracts were evaporated to dryness to obtain dry extracts (DE). The samples of DE $(10 \mathrm{mg})$ were dissolved in $1 \mathrm{~mL}$ of $70 \%$ aqueous methanol, filtered through a PTFE syringe filter $(25 \mathrm{~mm}, 0.2 \mu \mathrm{m}$, Vitrum, Czech Republic) and injected $(3 \mu \mathrm{L})$ into the UHPLC system.

The flavonoid content was determined as the total content of flavonoid aglycones obtained after acid hydrolysis. The samples $(500 \mathrm{mg}$ ) were first defatted by pre-extraction $(15 \mathrm{~min})$ with $20 \mathrm{~mL}$ chloroform, and then refluxed for $1 \mathrm{~h}$ with the mixture of $6 \mathrm{~mL} 36.5 \%(11.8 \mathrm{M}, w / v)$ hydrochloric acid and $30 \mathrm{~mL} 90 \%(v / v)$ aqueous methanol. Thus the hydrolytic solution consisted of $1.97 \mathrm{M}(70 \mathrm{~g} / \mathrm{L})$ hydrochloric acid and $75 \%$ aqueous methanol $(v / v)$. After filtration, the sample was extracted twice with $20 \mathrm{~mL}$ of $90 \%$ aqueous methanol for $10 \mathrm{~min}$. The combined hydrolyzates were diluted to $100 \mathrm{~mL}$ with methanol to obtain the hydrolyzed extract (HE).

For quantification of flavonoid aglycones and chlorogenic acid isomers, HE and CE were filtered through a PTFE syringe filter and injected $(20 \mu \mathrm{L})$ into the HPLC system. The determinations were performed after three separate extractions of each leaf sample, and each $\mathrm{HE}$ and $\mathrm{CE}$ were injected into the HPLC system in triplicate. 


\subsection{Phytochemical Profiling}

\subsubsection{UHPLC-PDA-ESI-QTOF-MS and HPLA-PDA Analyses}

UHPLC-PDA-ESI-QTOF-MS analyses of DE were performed on UHPLC-3000 RS system (Dionex, Dereieich, Germany) with a diode array detector with multiple wavelength (Thermo Fisher Scientific Inc., Waltham, MA, USA), and an ultrahighresolution hybrid quadrupole/time-of-flight mass spectrometer (UHR-Q-TOF-MS, Bruker Daltonics GmbH, Bremen, Germany) using an electrospray ionization (ESI) source operating in negative modes. Instrument control, data acquisition, and evaluation were done with the QTOFControl 3.2, HyStar 3.2, and Chromeleon 6.8.1 Chromatography Data System softwares, respectively. Separations were carried out on a Accucore C18 column $(150 \times 3.0 \mathrm{~mm}, 2.6 \mu \mathrm{m}$, Thermo Scientific). The mobile phase consisted of solvent A (water:formic acid, 100:0.1, $v / v$ ) and solvent $B$ (acetonitrile:formic acid, 100:0.1, $v / v$ ) with the elution profile as follows: 0-25 min, 4\%-10\% (v/v) B; 25-65 min, $10 \%-20 \%$ B; 65-73 min, 85\% B; 73-79 $\mathrm{min}, 85 \%-4 \%$; $79-85 \mathrm{~min}$, $4 \% \mathrm{~B}$. The flow rate was $0.3 \mathrm{~mL} / \mathrm{min}$. The column temperature was $25^{\circ} \mathrm{C}$. UV spectra were recorded over a range of 200-450 nm, chromatograms were acquired at 280, 320 and $360 \mathrm{~nm}$. The LC eluate was introduced directly into the ESI interface without splitting. ESI parameters: the nebuliser pressure was $14.5 \mathrm{psi}$; dry gas flow $8 \mathrm{~L} / \mathrm{min}$; dry temperature $200^{\circ} \mathrm{C}$; and capillary voltage $4.5 \mathrm{kV}$. Analysis was carried out using scan from $-m / z 50$ to 1500 . Compounds were analyzed in negative ion mode. The MS fragmentation was obtained in Auto MS/MS mode for the most abundant ion at the time. The identification of individual phenolic compounds was achieved by comparison of their retention times, UV-Vis spectra and MS profile with those of the available reference standards and data reported in the literature.

HPLC-PDA analyses of CE and HE were performed on a Waters 600E Multisolvent Delivery System (Waters, Milford, MA, USA) with a PDA detector (Waters 2998) scanning in the wavelength range of 220-550 nm; and a manual injector rheodyne, 7725i model (Rheodyne, Pittsburgh, PA, USA) with $20 \mu \mathrm{L}$ sample loop. The constant temperature of the column was maintained using a Jetstream Plus 5480 thermostat (Thermotechnic Products, Langenzersdorf, Austria).

\subsubsection{Determination of Total Flavonoid Content (TFC)}

The total flavonoid content in HE was determined using HPLC-PDA (see Section 3.4.1.) by the slightly modified method [44]. The analytical column was a C18 Nucleodur C-18 Gravity $(5 \mu \mathrm{m}$, $250 \times 4.6 \mathrm{~mm}$ i.d.; MN, Düren, Germany), guarded by a C18 Hypersil ODS pre-column $(5 \mu \mathrm{m}$, $4 \times 4 \mathrm{~mm}$ i.d.; Agilent Technologies, Santa Clara, CA, USA). The analysis was performed using the mobile phase consisted of solvent $A$ (water/orthophosphoric acid, 99.5:0.5 $\mathrm{v} / \mathrm{w}$ ), and solvent B (methanol) with the elution profile as follows: 0-16 $\min : 45 \%-65 \% \mathrm{~B}, 16.01-18 \mathrm{~min}: 45 \% \mathrm{~B}$ (equilibration). The flow rate was $1.4 \mathrm{~mL} / \mathrm{min}$ and the column temperature was set at $40{ }^{\circ} \mathrm{C}$. The compounds were monitored at $370 \mathrm{~nm}$, and their UV-Vis spectra were recorded for peak purity and identification tests. The aglycones QU and KA were identified by comparison of their UV-Vis spectra and retention times $\left(t_{R}=8.8\right.$ and $12.2 \mathrm{~min}$, respectively) with those of authentic standards. The flavonoid content (TFC) was calculated from the calibration curves of the external standards within the concentration ranges of approximately $2.5-85.2 \mu \mathrm{g} / \mathrm{mL}$ for QU and $0.6-20.0 \mu \mathrm{g} / \mathrm{mL}$ for KA.

\subsubsection{Determination of Chlorogenic Acid Isomers (CHAC)}

The total chlorogenic acid isomers in CE was determined by HPLC-PDA (see Section 3.4.1.) with some variations of method [35]. The analytical column was a C18 Ascentis ${ }^{\circledR}$ Express $(2.7 \mu \mathrm{m}$, $75 \times 4.6 \mathrm{~mm}$ i.d.; Supelco, Bellefonte, PA, USA), guarded by a C18 Ascentis ${ }^{\circledR} \mathrm{C} 18$ Supelguard column $(3 \mu \mathrm{m}, 20 \times 4 \mathrm{~mm}$ i.d.; Supelco). The mobile phase consisted of solvent A (water/orthophosphoric acid, 99.5:0.5 $\mathrm{v} / \mathrm{w}$ ) and solvent $\mathrm{B}$ (acetonitrile) with the elution profile as follows: 0-14 $\mathrm{min}, 6 \%-30 \% \mathrm{~B}(\mathrm{v} / \mathrm{v})$; 14-15 $\mathrm{min}, 30 \%-50 \% \mathrm{~B} ; 15-17 \mathrm{~min}, 50 \% \mathrm{~B} ; 17-18 \mathrm{~min}, 50 \%-6 \% \mathrm{~B} ; 18-21 \mathrm{~min}, 6 \%$ B (equilibration). The flow rate was $1.4 \mathrm{~mL} / \mathrm{min}$ and the column temperature was maintained at $25^{\circ} \mathrm{C}$. The chromatograms 
were recorded at $325 \mathrm{~nm}$ and the peaks of NCHA, CHA and CCHA were assigned based on the UV-Vis spectra and retention times ( $t_{R}=3.6,6.1$ and $6.8 \mathrm{~min}$, respectively) of the standard compounds. The contents of the isomers were calculated from the calibration curve of chlorogenic acid (CHA) obtained within the concentration ranges of $2.6-265.3 \mu \mathrm{g} / \mathrm{mL}$.

\subsubsection{Determination of Total Phenolic Content (TPC)}

The total phenolic content (TPC) in CE was determined according to the Folin-Ciocalteu (FC) method as described previously [44,45]. The results were expressed as $\mathrm{g}$ of Gallic acid equivalents per $100 \mathrm{~g}$ of dry weight of the plant material (\% GAE).

\subsubsection{Determination of Total Proanthocyanidin Content (TPAC)}

Determination of the total proanthocyanidin content (TPA) in CE was performed using the modified $n$-butanol/ $\mathrm{HCl}$ method of Porter et al. [35,46]. The results were expressed as $\mathrm{g}$ of cyanidin chloride equivalents per $100 \mathrm{~g}$ of dry weight of the plant material (\% CYE).

\subsection{Antioxidant Activity Testing}

\subsubsection{DPPH Free Radical Scavenging Assay}

The DPPH scavenging activity of CE was determined according to the method optimized earlier [45]. The analytical samples were prepared using serial dilutions of CE in $70 \%$ aqueous methanol $(v / v)$ to obtain the plant sample concentration of $13-40 \mu \mathrm{g} / \mathrm{mL}$ in the reaction medium. Finally, the $\mathrm{EC}_{50}$ values were calculated from five-point calibration curves by plotting the sample concentration in the reaction medium $(\mu \mathrm{g} / \mathrm{mL})$ versus the concentration $(\mu \mathrm{g} / \mathrm{mL})$ of remaining DPPH radical as determined from the DPPH calibration curve.

\subsubsection{Ferric Reducing Antioxidant Power (FRAP) Assay}

The determination of ferric reducing ability (FRAP) of CE was performed based on the original method [47] with slight modifications [48]. Prior to the analysis, the CE was diluted with 70\% aqueous methanol $(v / v)$ to the plant sample concentration of $5-10 \mu \mathrm{g} / \mathrm{mL}$ in the reaction medium. The activity was expressed in millimoles of $\mathrm{Fe}^{2+}$ produced by $1 \mathrm{~g}$ of the dry plant material as calculated from the calibration curve of ferrous sulfate.

\subsubsection{Superoxide Anion Radical $\left(\mathrm{O}_{2}^{\bullet-}\right)$ Scavenging Assay}

The capacity of $\mathrm{CE}$ to scavenge superoxide anion radical $\left(\mathrm{O}_{2}{ }^{--}\right)$was monitored using the xanthine/xanthine oxidase system with nitrobluetetrazolium (NBT) as described previously [49]. Before testing, the CE was evaporated to dryness and redissolved in PBS solution (without $\mathrm{Ca}^{2+}$, $\mathrm{Mg}^{2+}$ ) to obtain the plant sample concentration of $15-100 \mu \mathrm{g} / \mathrm{mL}$ in the reaction medium. In order to evaluate the possibility of direct interaction of $\mathrm{CE}$ with the enzyme, the uric acid production by xanthine oxidase was monitored at $295 \mathrm{~nm}$ [49] and no inhibitory effect on the enzyme was observed. The $\mathrm{SC}_{50}$ values for scavenging capacity were calculated from five-point calibration curves by plotting the sample concentration in the reaction medium $(\mu \mathrm{g} / \mathrm{mL})$ versus the percentage of $\mathrm{O}_{2}{ }^{\bullet-}$ radical.

\subsubsection{Hydrogen Peroxide $\left(\mathrm{H}_{2} \mathrm{O}_{2}\right)$ Scavenging Assay}

The ability of $\mathrm{CE}$ to scavenge hydrogen peroxide $\left(\mathrm{H}_{2} \mathrm{O}_{2}\right)$ was determined according to the chemiluminescence method as described previously [49]. Before testing, the CE was evaporated to dryness and redissolved in PBS solution (without $\mathrm{Ca}^{2+}, \mathrm{Mg}^{2+}$ ) to obtain the sample concentration of $15-100 \mu \mathrm{g} / \mathrm{mL}$ in the reaction medium. The $\mathrm{SC}_{50}$ values were calculated from five-point calibration curves by plotting the sample concentration in the reaction medium $(\mu \mathrm{g} / \mathrm{mL})$ versus the percentage of $\mathrm{H}_{2} \mathrm{O}_{2}$. 


\subsection{Statistical and Data Analysis}

The results were expressed as means \pm standard deviation (SD) of triplicate determinations. The statistical analyses (calculation of SD, one-way analysis of variance, HSD Tukey tests, linearity studies and hierarchical cluster analysis) were performed using the Statistica12Pl software for Windows (StatSoft Inc., Krakow, Poland), with $p$ values less than 0.05 being regarded as significant.

\section{Conclusions}

The current study demonstrates that the leaf samples of twelve Cotoneaster species cultivated in Poland possess significant and dose-dependent in vitro SET- and HAT-type antioxidant activities, which positively correlate with their total phenolic content (TPC). Among the Cotoneaster phenolics, the proanthocyanidins were found to be primarily responsible for the tested activity. The leaves of C. zabelii, C. splendens, C. bullatus, C. divaricatus, C. hjelmqvistii and C. lucidus (samples grouped in the cluster CL-1), presenting the highest phenolic content and antioxidant activity, were selected as the most valuable sources of powerful antioxidants with great potential for the use in pharmaceutical, cosmetic and food industries. However, further detailed studies are needed to explore the molecular structure and antioxidant capacity of their individual phenolic constituents as well as to clarify the possible toxicity and other in vivo biological properties of the tested Cotoneaster extracts.

Supplementary Materials: Supplementary materials can be accessed at: http://www.mdpi.com/1420-3049/21/ 6/688/s1.

Acknowledgments: This work was financially supported by the Medical University of Lodz (internal grant no 503/3-022-01/503-36-001). The authors would like to thank the staff of the Botanical Garden in Lodz and Forestry Experimental Station of Warsaw University of Life Sciences in Rogow for providing and authenticating the plant material.

Author Contributions: A.K. designed the research, performed the phytochemical and antioxidant activity studies, analyzed the data and wrote the paper. D.Z., G.B., J.O. and A.M. performed phytochemical studies. P.M. and A.O. performed antioxidant activity studies. M.A.O. co-designed the research, revised the manuscript and helped in interpretation of the results.

Conflicts of Interest: The authors declare no conflict of interest.

\section{References}

1. Aseervatham, G.S.B.; Sivasudha, T.; Jeyadevi, R.; Ananth, D.A. Environmental factors and unhealthy lifestyle influence oxidative stress in humans-An overview. Environ. Sci. Pollut. Res. 2013, 20, 4356-4369. [CrossRef] [PubMed]

2. Pandey, K.B.; Rizvi, S.I. Plant polyphenols as dietary antioxidants in human health and disease. Oxid. Med. Cell. Longev. 2009, 2, 270-278. [CrossRef] [PubMed]

3. Li, A.N.; Li, S.; Li, H.B.; Xu, D.P.; Xu, X.R.; Chen, P. Total phenolic contents and antioxidant capacities of 51 edible and wild flowers. J. Funct. Food 2014, 6, 319-330. [CrossRef]

4. Fu, L.; Xu, B.-T.; Xu, X.-R.; Gan, R.-Y.; Zhang, Y.; Xia, E.-Q.; Li, H.-B. Antioxidant capacities and total phenolic contents of 62 fruits. Food Chem. 2011, 129, 345-350. [CrossRef]

5. Edwards, J.E.; Brown, P.N.; Talent, N.; Dickinson, T.A.; Shipley, P.R. A review of the chemistry of the genus Crataegus. Phytochemistry 2012, 79, 5-26. [CrossRef] [PubMed]

6. Denev, P.N.; Kratchanov, C.G.; Ciz, M.; Lojek, A.; Kratchanova, M.G. Bioavailability and antioxidant activity of black chokeberry (Aronia melanocarpa) polyphenols: In vitro and in vivo evidences and possible mechanisms of action: A review. Compr. Rev. Food Sci. Food Saf. 2012, 11, 471-489. [CrossRef]

7. Verma, R.; Gangrade, T.; Punasiya, R.; Ghulaxe, C. Rubus fruticosus (blackberry) use as an herbal medicine. Pharmacogn. Rev. 2014, 8, 101-104. [PubMed]

8. Liaudanskas, M.; Viškelis, P.; Raudonis, R.; Kviklys, D.; Uselis, N.; Janulis, V. Phenolic composition and antioxidant activity of Malus domestica leaves. Sci. World J. 2014, 2014, 1-11. [CrossRef] [PubMed]

9. Dickoré, W.B.; Kasperek, G. Species of Cotoneaster (Rosaceae, Maloideae) indigenous to, naturalising or commonly cultivated in Central Europe. Willdenowia 2010, 40, 13-45. [CrossRef]

10. Jerzak, E. Cotoneaster Species Cultivated in Poland (in Polish); Officina Botanica: Krakow, Poland, 2007. 
11. Slabaugh, P.E.; Shaw, N.L. Cotoneaster Medik. The Woody Plant Seed Manual; Bonner, F.T., Karrfalt, R.P., Eds.; U.S. Department of Agriculture, Forest Service: Washington, DC, USA, 2008; pp. 442-446.

12. Holzer, V.M.D.; Lower-Nedza, A.D.; Nandintsetseg, M.; Batkhuu, J.; Brantner, A.H. Antioxidant constituents of Cotoneaster melanocarpus Lodd. Antioxidants 2013, 2, 265-272. [CrossRef] [PubMed]

13. Esmaeili, S.; Ghiaee, A.; Naghibi, F.; Mosaddegh, M. Antiplasmodial activity and cytotoxicity of plants used in traditional medicine of Iran for the treatment of fever. Iran J. Pharm. Res. 2015, 14, 103-107. [PubMed]

14. Azadbakht, M.; Pishva, N.; Mohammadi-Samani, S.; Alinejad, F. The effect of purgative manna on the infant jaundice. Iran. J. Pharm. Sci. 2005, 1, 95-100.

15. Yaghooti, F.; Sani, A.M. Antibacterial activity of methanolic extracts from Cotoneaster nummularioides, Cynodon dactylon and Cardaria draba on typical food-borne pathogens. Inter. J. Biosci. 2015, 6, 349-356.

16. Zengin, G.; Uysal, A.; Gunes, E.; Aktumsek, A. Survey of phytochemical composition and biological effects of three extracts from a wild plant (Cotoneaster nummularia Fisch. et Mey.): A potential source for functional food ingredients and drug formulations. PLoS ONE 2014, 9, e113527. [CrossRef] [PubMed]

17. Sokkar, N.; El-Gindi, O.; Sayed, S.; Mohamed, S.; Ali, Z.; Alfishawy, I. Antioxidant, anticancer and hepatoprotective activities of Cotoneaster horizontalis Decne extract as well as $\alpha$-tocopherol and amygdalin production from in vitro culture. Acta. Physiol. Plant 2013, 35, 2421-2428. [CrossRef]

18. Mohamed, S.A.; Sokkar, N.M.; El-Gindi, O.; Ali, Z.Y.; Alfishawy, I.A. Phytoconstituents investigation, anti-diabetic and anti-dyslipidemic activities of Cotoneaster horizontalis Decne cultivated in Egypt. Life Sci. J. 2012, 9, 394-403.

19. El-Mousallamy, A.M.; Hussein, S.A.; Merfort, I.; Nawwar, M.A. Unusual phenolic glycosides from Cotoneaster orbicularis. Phytochemistry 2000, 53, 699-704. [CrossRef]

20. Palme, E.; Bilia, A.R.; Morelli, I. Flavonols and isoflavones from Cotoneaster simonsii. Phytochemistry 1996, 42, 903-905. [CrossRef]

21. Palme, E.; Bilia, A.R.; de Feo, V.; Morelli, I. Flavonoid glycosides from Cotoneaster thymaefolia. Phytochemistry 1994, 35, 1381-1382. [CrossRef]

22. Khan, S.; Riaz, N.; Afza, N.; Malik, A.; Aziz-ur-Rehman; Iqbal, L.; Lateef, M. Antioxidant constituents from Cotoneaster racemiflora. J. Asian Nat. Prod. Res. 2009, 11, 44-48. [CrossRef] [PubMed]

23. Sati, S.C.; Sati, M.; Sharma, A.; Joshi, M. Isolation and characterisation of phenolics from the roots of Cotoneaster acuminatus and determination of their antimicrobial activity. Int. J. Pharm. Pharm. Sci. 2010, 2, $58-60$.

24. Kokubun, T.; Harborne, J.B. Phytoalexin induction in the sapwood of plants of the Maloideae (Rosaceae): Biphenyls or dibenzofurans. Phytochemistry 1995, 40, 1649-1654. [CrossRef]

25. Kokubun, T.; Harborne, J.B.; Eagles, J.; Waterman, P.G. Dibenzofuran phytoalexins from the sapwood of Cotoneaster acutifolius and five related species. Phytochemistry 1995, 38, 57-60. [CrossRef]

26. Pashinina, L.T.; Chumbalov, T.K.; Sheichenko, V.I.; Shukenova, R.Z. Dimeric proanthocyanidins of Cotoneaster oligantha. Chem. Nat. Comp. 1978, 14, 166-172. [CrossRef]

27. Khan, S.; Yasmeen, S.; Afza, N.; Malik, A.; Iqbal, L.; Lateef, M. Cotonoates A and B, new aromatic esters from Cotoneaster racemiflora. Z. Naturforsch. 2008, 63b, 1219-1222.

28. Khan, S.; Wang, Z.; Wang, R.; Zhang, L. Horizontoates A-C: New cholinesterase inhibitors from Cotoneaster horizontalis. Phytochem. Lett. 2014, 10, 204-208. [CrossRef]

29. Clifford, M.N.; Knight, S.; Kuhnert, N. Discriminating between the six isomers of dicaffeoylquinic acid by LC-MS ${ }^{n}$. J. Agric. Food Chem. 2005, 53, 3821-3832. [CrossRef] [PubMed]

30. Nandutu, A.M.; Clifford, M.; Howell, N.K. Analysis of phenolic compounds in Ugandan sweet potato varieties (NSP, SPK AND TZ). Afr. J. Biochem. Res. 2007, 1, 29-36.

31. Hamed, A.I.; Al-Ayed, A.S.; Moldoch, J.; Piacenta, S.; Oleszek, W.; Stochmal, A. Profiles analysis of proanthocyanidins in the argun nut (Medemia argun-An ancien Egyptian palm) by LC-ESI-MS/MS. J. Mass Spectrom. 2014, 49, 306-315. [CrossRef] [PubMed]

32. Prior, R.L.; Wu, X.; Schaich, K. Standardized methods for the determination of antioxidant capacity and phenolics in foods and dietary supplements. J. Agric. Food Chem. 2005, 53, 4290-4302. [CrossRef] [PubMed]

33. Apak, R.; Güçlü, K.; Demirata, B.; Ozyürek, M.; Celik, S.E.; Bektaşoğlu, B.; Berker, K.I.; Ozyurt, D. Comparative evaluation of various total antioxidant capacity assays applied to phenolic compounds with the CUPRAC assay. Molecules 2007, 12, 1496-1547. [CrossRef] [PubMed] 
34. Nowak, R.; Gawlik-Dziki, U. Polyphenols of Rosa L. leaves extracts and their radical scavenging activity. Z. Naturforsch. C. 2007, 62, 32-38. [CrossRef] [PubMed]

35. Olszewska, M.A.; Nowak, S.; Michel, P.; Banaszczak, P.; Kicel, A. Assessment of the content of phenolics and antioxidant action of inflorescences and leaves of selected species from the genus Sorbus sensu stricto. Molecules 2010, 15, 8769-8783. [CrossRef] [PubMed]

36. Thi, N.D.; Hwang, E.S. Bioactive compound contents and antioxidant activity in Aronia (Aronia melanocarpa) leaves collected at different growth stages. Prev. Nutr. Food Sci. 2014, 19, 204-212. [CrossRef] [PubMed]

37. Nour, V.; Trandafir, I.; Cosmulescu, S. Antioxidant capacity, phenolic compounds and minerals content of blackcurrant (Ribes nigrum L.) leaves as influenced by harvesting date and extraction method. Ind. Crops Prod. 2014, 53, 133-139. [CrossRef]

38. Kumar, S.; Pandey, A.K. Chemistry and biological activities of flavonoids: An overview. Sci. World J. 2013, 2013, 1-16. [CrossRef] [PubMed]

39. Beecher, G.R. Proanthocyanidins: Biological activities associated with human health. Pharm. Biol. 2004, 42, 2-20. [CrossRef]

40. Zhou, H.C.; Tam, N.F.; Lin, Y.M.; Ding, Z.H.; Chai, W.M.; Wei, S.D. Relationships between degree of polymerization and antioxidant activities: A study on proanthocyanidins from the leaves of a medicinal mangrove plant Ceriops tagal. PLoS ONE 2014, 9, e107606.

41. Nassiri-Asl, M.; Hosseinzadeh, H. Review of the pharmacological effects of Vitis vinifera (Grape) and its bioactive compounds. Phytother. Res. 2009, 23, 1197-1204. [CrossRef] [PubMed]

42. Leigh, M.J. Health benefits of grape seed proanthocyanidin extract (GSPE). Nutr. Noteworthy 2003, 6, 1-5.

43. Nagels, L.; van Dongen, W.; de Brucker, J.; de Pooter, H. High-performance liquid chromatographic separation of naturally occurring esters of phenolic acids. J. Chromatogr. A 1980, 187, 181-187. [CrossRef]

44. Kicel, A.; Wolbiś, M. Phenolic content and DPPH radical scavenging activity of the flowers and leaves of Trifolium repens. Nat. Prod. Commun. 2013, 1, 99-102.

45. Olszewska, M.A.; Michel, P. Antioxidant activity of inflorescences, leaves and fruits of three Sorbus species in relation to their polyphenolic composition. Nat. Prod. Res. 2009, 23, 1507-1521. [CrossRef] [PubMed]

46. Porter, L.J.; Hrstich, L.N.; Chan, B.G. The conversion of procyanidins and prodelphinidins to cyanidin and delphinidin. Phytochemistry 1986, 25, 223-230. [CrossRef]

47. Benzie, I.F.; Strain, J.J. The ferric reducing ability of plasma (FRAP) as a measure of "Antioxidant Power": The FRAP assay. Anal. Biochem. 1996, 239, 70-76. [CrossRef] [PubMed]

48. Kicel, A.; Olszewska, M.A. Evaluation of antioxidant activity, and quantitative estimation of flavonoids, saponins and phenols in crude extract and dry fractions of Medicago lupulina aerial parts. Nat. Prod. Commun. 2015, 10, 483-486. [PubMed]

49. Granica, S.; Czerwińska, M.E.; Piwowarski, J.P.; Ziaja, M.; Kiss, A.K. Chemical composition, antioxidative and anti-inflammatory activity of extracts prepared from aerial parts of Oenothera biennis L. and Oenothera paradoxa Hudziok obtained after seeds cultivation. J. Agric. Food Chem. 2013, 61, 801-810. [CrossRef] [PubMed]

Sample Availability: Plant samples are available from the authors.

(C) 2016 by the authors; licensee MDPI, Basel, Switzerland. This article is an open access article distributed under the terms and conditions of the Creative Commons Attribution (CC-BY) license (http://creativecommons.org/licenses/by/4.0/). 